\title{
The Impacts of Global Budget Payment System on Public Hospitals and Countermeasures
}

\author{
Mingju Chen \\ Department of Thoracic Surgery, Qilu Hospital Shandong University, Jinan, China \\ chenmingju2015@163.com
}

Keywords: Medical insurance global budget system; Public hospitals; Health care reform

\begin{abstract}
Under the basic medical insurance system, the high cost of getting a treatment and difficulty in seeing a doctor have been resolved to some extent, but the reasonable control of medical insurance costs have remained an unresolved problem for many years. Medical insurance payment is one of the core concerns of the Medicare problem. To a certain extent, Global Budget has exerted a beneficial influence in resolving this problem and produced considerable impact on the development of the hospital. Through data comparison, this paper conducts an in-depth analysis of the beneficial and adverse effects global budget exerted on public hospitals and offers some suggestions for deepening health care reform and realize the healthy development of the hospital.
\end{abstract}

\section{Current Situation and Developing Trend of Global Budget Payment System}

Current Situation of Global Budget in China. Global budget Payment System of medical insurance refers to a system that the government prepays the medical expense to relevant medical service sectors according to some standards established by health insurance companies before the actual medical costs incurred. In the given period, the payment standard is fixed, later it will be adjusted according to actual situation. Global budget payment system of medical insurance includes payment by disease group and by capitation payments.

According to the payment standards of medical expenses for a certain period of time and the comprehensive service of a certain medical institution, such as size, technology, patient number and the number of medical services, government and medical insurance institutions have determined a certain number to pay for health institutions and take it as the prepaid limit. Once the total amount of prepaid payment is finalized, the medical income of a hospital will have no variation, even if the number of service has changed. If any losses is generated in the course of business, the medical service institutions will receive no additional compensation, the losses must be borne by the hospital itself. Thus, effective and reasonable immobilization total budget is crucial to ensure the operation of the global budget payment system.

Development Trend of Global Budget. Global Budget Is Inevitable. As a conditional guarantee of national medical treatment, global budget health insurance is bound to step onto the stage to protect citizens having access to become a public administration beneficiary in modern society. Through government unified management and control, this system can manage the prepaid fund in a proper and effective way. At present, with the rapid development of society, the defects of post-paid system gradually emerged and highlighted, which contains the incapacity to coordinate the relationship among patients, hospitals and the health insurance fund management institutions. Therefore, the prepaid system instead of the postpaid system is the only way of deepening health care reform, and the premise of progressively realizing DRGs.

Site-specific Mixed Payment System Development Becomes Inevitable. Payment system need constantly be reformed on order to meet the social needs of public administration. It should take multiple factors into consideration, including the regional economic development, health resources, 
health insurance system, the level of information and social conditions etc. Besides, reform and innovation in payment should be on the basis of local conditions and in accordance with policy requirements. Through the close communication and coordination between medical insurance fund management institutions and hospitals, the single payment system shall be improved and reformed. The development of hybrid payment system can appropriately control costs, effectively reduce the cost pressure of medical patient, and at the same time satisfy the fairness of social care in the process of medical services.

Currently, no single country can establish a insurance payment system only by virtue of a certain kind of insurance payment regime. For example, the DRGs system adopted in the United States have combined many payment methods to decide the prepaid payment of medical expenses, including by capitation and by services. Though multiple methods combination, this diversified payment method can fully avoid the disadvantages of each specific one.

The Government should Introduce Some Supporting Measures. Health care reform is an important system engineering, whose smooth operation needs the introduction of a number of supporting measures during the reform process, including the reform of public hospitals, social policy to establish hospitals, medical services pricing system etc.

\section{The Impact of Global Budget on Public Hospitals}

Research Object and Statistical Analysis Methods. Shanghai represents the vanguard of China's reform; therefore the data collected from Shanghai hospital have significant representative meaning. Besides, Xuzhou, as a typical resource-exhausted old industrial base, its data can also represent the medical level of most areas in China. Therefore, this study mainly takes medical data collected from Shanghai and Xuzhou, among which the main sources are out-patient/emergency number, number of discharged patients, and Medicare total cost in Shanghai tertiary hospital during 2012-2014 as well as income, assets and liabilities of a traditional Chinese medicine hospital in Xuzhou during 2010-2013.

The main research method is to use SPSS software for descriptive analysis of the data and drawing the index variation trend.

Table 1 shows the Changes of out-patient/emergency number and number of discharged patients in Shanghai tertiary hospital during 2012-2014. Through Figure analysis, it is clear that the ratio of outpatient/emergency number and the number of discharged patients in tertiary hospitals are constantly increasing.

Table 1 Changes of out-patient/emergency number and number of discharged patients in Shanghai tertiary hospital during 2012-2014(\%)

\begin{tabular}{|c|c|c|c|c|}
\hline & \multicolumn{2}{|c|}{$\begin{array}{c}\text { Out- } \\
\text { patient/emergency } \\
\text { number }\end{array}$} & \multicolumn{2}{|c|}{$\begin{array}{c}\text { Number of } \\
\text { discharged patients }\end{array}$} \\
\cline { 2 - 5 } r & Yo & $\begin{array}{c}\text { Ratio of it to } \\
\text { total number } \\
\text { of out- } \\
\text { patient/emerg } \\
\text { ency patient }\end{array}$ & YoY & $\begin{array}{c}\text { Ratio of it } \\
\text { to total } \\
\text { number of } \\
\text { discharged } \\
\text { patients }\end{array}$ \\
\hline $\begin{array}{c}201 \\
2\end{array}$ & 9.7 & 55.2 & 9.6 & 44.8 \\
\hline $\begin{array}{c}201 \\
3\end{array}$ & $\begin{array}{c}11 . \\
0\end{array}$ & 55.9 & 10.0 & 48.0 \\
\hline 201 & 11. & 58.5 & 11.9 & 46.7 \\
4 & 6 & & & \multicolumn{2}{|c|}{} \\
\hline
\end{tabular}


In terms of the medical insurance expenses, since 2012, public hospitals have witnessed an increasing outpatient and emergency costs under the influence of medical insurance global budget system, but the proportion of those cost to the total health care costs was constantly reducing (See Table 2).

Table 2 Changes of Medicare total cost in Shanghai tertiary hospital during 2012-2014

\begin{tabular}{|l|l|l|l|}
\hline Year & $\begin{array}{l}\text { Total cost of } \\
\text { health } \\
\text { insurance } \\
\text { (billion) }\end{array}$ & $\begin{array}{l}\text { YoY }(\% \\
)\end{array}$ & $\begin{array}{l}\text { Ratio of health } \\
\text { insurance to } \\
\text { total costs }(\%)\end{array}$ \\
\hline 2012 & 156.1 & 15.8 & 35.9 \\
\hline 2013 & 171.3 & 16.3 & 34.2 \\
\hline 2014 & 192.1 & 16.8 & 33.9 \\
\hline
\end{tabular}

As shown in Table 3, during 2010-2013, the average annual revenue growth rate was $12 \%$, the average annual net profit growth was $0.004 \%$, showing an steady situation. However, assets decreased 247.71 million between 2010 and 2011 and later exhibited a significant increasing trend, as the system change of public institutions caused some variation in calculating indexes.

Table 3 Income, assets and liabilities of a traditional Chinese medicine hospital in Xuzhou during 2010 - 2013 (million)

\begin{tabular}{|c|c|c|c|c|c|}
\hline Year & $\begin{array}{c}\text { Net } \\
\text { margi } \\
\mathrm{n}\end{array}$ & $\begin{array}{c}\text { Incom } \\
\mathrm{e}\end{array}$ & $\begin{array}{c}\text { Total } \\
\text { assets }\end{array}$ & $\begin{array}{c}\text { Total } \\
\text { liabiliti } \\
\text { es }\end{array}$ & $\begin{array}{c}\text { Asset- } \\
\text { liability } \\
\text { ratio } \\
(\%)\end{array}$ \\
\hline 2010 & 21.55 & 351.86 & 498.43 & 114.86 & 23.04 \\
\hline 2011 & 25.10 & 390.01 & 250.72 & 84.03 & 33.52 \\
\hline 2012 & 25.29 & 465.48 & 295.83 & 112.35 & 37.98 \\
\hline 2013 & 25.49 & 551.88 & 331.41 & 120.52 & 36.37 \\
\hline Mean & 24.36 & 439.81 & 355.82 & 105.61 & 29.68 \\
\hline
\end{tabular}

Through the above data analysis, the impact of medical insurance global budget system for public hospitals can be summarized into two aspects: the beneficial effects and the adverse effects.

Analysis of Favorable Factors. To Enhance Medical Resource Utilization, Reduce Health Care Administrative Cost. Table 1: The number of outpatient and discharged patients are increasing significantly, indicating that public hospitals have improved resource utilization under the global budget medical insurance system. With the rising living standards and consumption, the operation and maintenance cost of hospital is also increasing, the huge medical management and service cost creates a negative impact on the development of public hospital service levels. Global budget system can urge the hospital to obtain maximum profitability and improve resource utilization, improving internal management and waste control. Innovation management on the other hand also reduces the medical management costs.

To Promote the Active Participation of Public Hospitals in Health Care Management, and Enhance Their Cost Control Initiative. From the data change in Table 2 and Table 3, it can be concluded that under the global budget system, public hospitals has further enhanced the overall cost management awareness. In order to mitigate risks, cost control of hospital management has become more reasonable. Medical service institutions themselves take control of the medical costs, which can effectively reduce the cost of medical insurance management. 
Analysis of Adverse Factors. The Working Enthusiasm of the Medical Staff. Under global budget system, the profits of medical institutions will be reduced with the increased number of Medicare patients admitted to hospital admission, which is not conducive to the enthusiasm of the medical staff. At the same time, this system shall limit the use of expensive treatment services, increasing the difficulty of treatment. Doctors have to consider the total quota while taking patients' satisfaction into consideration.

Medical Service Quality and Efficiency. The global budget approach would inevitably lead to the weakening role of the market; doctors' service efficiency will unconsciously slow down, mitigating the initiative of hospitals and relevant institutions in providing medical services as well as reducing the occurrence of associated overruns behavior.

Tripartite Contradiction among Doctors, Patients and Insurance. When Medicare payments to the medical institutions is a fixed amount, health care providers has to endure a certain extent limitations when prescribe or give treatment. However, some Medicare patients don't understand the working mechanism of health care system, which causes many contradictions between the patients and doctors. In addition, the complexity of the disease reviewed by the medical insurance agencies and some other aspects also tends to cause contradictory and conflicts.

\section{Suggestions for Public Hospitals under Global Budget System}

Cultivate Medical Security Awareness. The basic medical security is the fundamental principle of implementing global budget health insurance, which has to be obeyed by all institutions whether it is health care management agency, the insured patients or the medical services providers. Relevant medical personnel must be promptly improve and update their knowledge of basic medical care, reasonable medication and treatment. As long as the patients' medical expenses pressure has been relieved, the medical-related services will keep healthy and sustainable development and improvement.

Establish a Consciousness of Service Treatment. Medical institutions must define a clearly positioning for their services and themselves, if necessary conducting some appropriate adjustments to improve service models and service concept. Medical service providers need to establish a correct sense of service, overcoming difficulties with excellent service quality service and enthusiasm, which requires long-term education and good management atmosphere.

Strengthen the Training of Health Care Workers. As lack of knowledge about Medicare policy is the major trigger of the contradictions between patients and doctors/caregivers, it is necessary to strengthen the education and training work of health insurance policy. Through training, the medical personnel can deepen their understanding of health insurance policy, more easily answer the patients' question about medical insurance, ensuring the patients and their friends can get a satisfactory consultation process. The hospital should give a regular training for the majority of personnel in order to improve their working capacity, for example, it can sent grass-roots workers to a higher level medical service institutions to get trained or select the elites to the grass-roots health care center to accumulate experience.

Enhance Health Care Policy Advocacy. The hospital should enhance the health insurance policy advocacy, establish a good doctor-patient relationship and communication mechanism to preventing and resolving conflicts between doctors and patients. As patients are more concerned about the latest public health insurance related laws, regulations and policies, the hospital can post those latest policies in a prominent position of the hospital, so that all doctors and patients can improve the comprehensive understanding of relevant theoretical knowledge of health insurance and the actual operation. In this way, the patients' satisfaction for medical treatment will be improved and a positive image for the hospital will be established. 


\section{Conclusion}

Currently, medical care payment in the world are mainly carried out by means of capitation, global budget, DRGs etc. A variety of medical payment methods have been constantly studied and discussed, various reform program and proposals continuously been put forward. The general trend includes prepayment model and the hybrid payment model. The global budget model has shown a prominent outcome in the public hospitals Medicare payment reform, but the function of mixed payment still need to be further improved, therefore, modular method of payment is the future development tendency. Under the premise of ensuring basic medical care, medical personnel should establish a correct sense of service and strengthen policy advocacy efforts, so that the majority of patients can understand the

Medicare health insurance policy and the relationship between hospital, patient and insurance will be more coordinated.

\section{References}

[1] Liu Weihua. The Impacts of Global Budget on Hospital development and Countermeasures [J]. China Urban Economy, 2011, (9); 35-36.

[2] Zhou Yanyang, Liu Jia, Liu Tianhu. On Management Measures to Improving the Quality of Medical Service [J] Modern Preventive Medicine, 2007, 34 (9): 17-25.

[3] Luo Huimin. Analysis on the Influence of Medical Insurance System on Curbing the Unreasonably Increase of Medical Expenses [J]. Chinese Medical Insurance, 2010, (11): 57-59.

[4] Yu Guangjun, Zhao Rong, Zheng Peiyong et. The influence of Global Budget Shanghai Implemented in Shanghai on Tertiary Hospital [J]. China Hospital, 2013, 17 (19): 1-3.

[5] Zhang Xiaoyu, Chen Min, Zhou Lin et. Operational Management Strategies of Medical Institutions under Global Budget System [J]. Chinese Journal of Aesthetic Medicine 2012, 21 (1):481-483. 